\title{
Los archivos diocesanos: análisis de series documentales e importancia para la investigación histórica
}

\author{
Agustín Vivas Moreno * \\ María Guadalupe Pérez Ortiz **
}

Artículo recibido:

13 de marzo de 2013.

Artículo aceptado:

9 de mayo de 2013.

\section{RESUMEN}

Desde su nacimiento en la época tridentina, los archivos diocesanos se han convertido en garantes de una importantísima parte de la documentación generada por la Iglesia católica, la que concierne a su obispo. Por medio del presente trabajo nos proponemos conocer, al menos someramente, la historia de estos archivos y su cuadro de clasificación documental, accediendo a sus secciones y series documentales más relevantes, así como ofrecer líneas de investigación que puedan servir a los investigadores para conocer contenidos históricos que se custodian específicamente en estos archivos.

* Universidad de Extremadura, España. avivas@alcazaba.unex.es

** Biblioteca del Seminario Metropolitano de San Atón, Badajoz, España.

INVESTIGACIÓN BIBLIOTECOLÓGICA, Vol. 29, Núm.65, enero/abril, 2015, México, ISSN: 0187-358X. pp. 73-99 
Palabras clave: Archivos diocesanos; Archivos episcopales; Clasificación documental; Cuadro de clasificación; Líneas de investigación; Series documentales.

\section{Abstract}

Analysis of documentary series held in Diocesan Archives and their importance to historical research Agustín Vivas-Moreno and María-Guadalupe Pérez-Ortiz

From its inception in the Tridentine era, the Diocesan Archive have safeguarded the most important papers associated with its Bishop produced by the Roman Catholic Church. This study provides and initial look of the history of these files, their documentary classification framework -allowing access to their most relevant sections and series, while also suggesting lines of research into the historical record preserved therein.

Keywords: Diocesan Files; Episcopal Files; Documentary Classification; Classification Picture; Investigation Lines; Documentary Series.

\section{INTRODUCCIÓN. LOS ARCHIVOS DIOCESANOS EN EL MARCO DE LOS ARCHIVOS ECLESIÁSTICOS}

L os archivos diocesanos o episcopales son, en líneas generales, los custodios de la documentación producida por el obispo y su curia en el desarrollo de sus múltiples competencias. Son, sin lugar a duda y a pesar de su tardío nacimiento, como posteriormente veremos, archivos consolidados que custodian una parte importantísima de la historia de la Iglesia.

En consecuencia, pretendemos con este trabajo analizar dichos archivos, confeccionar un cuadro de clasificación para la documentación que encierran, analizar sus principales series documentales y examinar aquellos contenidos que son más relevantes para la investigación histórica. Sin embargo, para ello creemos conveniente, en primer lugar, ubicar a los archivos diocesanos en el marco contextual de los archivos eclesiásticos, dado que la tipología de éstos ha sido debatida y sistematizada de forma diversa en momentos diferentes. 
La Iglesia católica cuenta con varias clasificaciones para encuadrar sus archivos, y aunque ciertamente algunas son muy similares, otras incluyen notorias diferencias que se deben, en cierto modo, al momento en el que fueron llevadas a término. Es muy importante reseñar que en estas categorizaciones se utilizan diferentes criterios de clasificación archivísticos, hecho sustancial que da lugar a segmentaciones en las que se aprecian desacuerdos. En ningún caso se trata de clasificaciones contradictorias sino concordantes en la diversidad de criterios y además, no se trata de clasificaciones excluyentes sino que admiten criterios incorporados. Todas ellas, pues, son válidas y aprovechables. A continuación procederemos muy brevemente a su exposición:

- Código de Derecho Canónico de 1917. Se trata del primer intento efectuado por la Iglesia para clasificar sus archivos. Establece: diocesano, secreto, histórico, parroquial, de la Iglesia catedral, de las colegiatas, de las fundaciones y de las demás iglesias. ${ }^{1}$

- Nunciatura Apostólica Española. "Los archivos eclesiásticos españoles podrán clasificarse en episcopales, catedralicios, parroquiales, monacales y de fundaciones piadosas". ${ }^{2}$

- Diccionario de Historia Eclesiástica. Bajo la entrada "archivo" accedemos al siguiente listado: A. Vaticano, monacales, catedralicios, de seminarios, parroquiales y de las Cruzadas. ${ }^{3}$

- Código de Derecho Canónico de 1983. Basándose en la estructura expuesta en el anterior código, establece los siguientes tipos de archivos: diocesano, secreto, histórico, de la Iglesia catedral, las colegiatas y demás iglesias de la diócesis, de las fundaciones, de los Institutos de vida consagrada y de las demás instituciones. ${ }^{4}$

- Diccionario del Patrimonio Cultural de la Iglesia. En el diccionario queda recogida la siguiente clasificación: diocesanos, secreto, de catedrales, colegiatas y parroquias, de la Conferencia Episcopal. ${ }^{5}$

- Asociación de Archiveros de la Iglesia (1997). A pesar del tiempo transcurrido desde su promulgación hasta el día de hoy, puede ser considerada como una de las más pertinentes clasificaciones con las que cuenta la Iglesia católica. En ella, los archivos serán organizados atendiendo a

1 Véase Código de Derecho Canónico de 1917.

2 "Carta circular de la Nunciatura Apostólica en España a los Reverendísimos Prelados sobre la reorganización de los archivos eclesiásticos (1929)”, pp. 231-240.

3 Q. Aldea Vaquero, T. Marín Martínez y J. Vives Gatell, Diccionario de Historia Eclesiástica, pp. 82-85.

4 Véase Código de Derecho Canónico de 1983.

5 D. Iguacen Borau, Diccionario del patrimonio cultural de la Iglesia, pp. 140-143. 
varios criterios: antigüedad, ámbito eclesiástico y función que desempeñan. ${ }^{6}$

a) Según su antigüedad: parroquiales y episcopales, monacales y de órdenes religiosas, catedralicios, del cabildo y de centros educativos del clero, de grupos y asociaciones de fieles (cofradías, hermandades) e instituciones hospitalarias y escolares.

b) Según su ámbito eclesiástico: diocesanos, parroquiales, de entes no sometidos al obispo diocesano y de personas jurídicas.

c) Según la función que desempeñan: archivos corrientes, históricos y secretos diocesanos.

- Manual de Archivos Eclesiásticos. Respecto al tema que nos compete, se incluye una amplia clasificación en la que se consideran: parroquiales, capitulares o catedralicios, episcopales o diocesanos, monásticos, de órdenes religiosas de vida activa y de seminarios. ${ }^{7}$

Veamos conjuntamente las clasificaciones expuestas:

Tabla I. Tipologías de archivos eclesiásticos

\begin{tabular}{|c|c|c|c|c|c|c|}
\hline \multicolumn{7}{|c|}{ Tipologías de archivos eclesiásticos } \\
\hline $\begin{array}{c}\text { C. Derecho } \\
\text { Canónico } \\
(1917)\end{array}$ & $\begin{array}{c}\text { Nunciatura } \\
\text { (1929) }\end{array}$ & \begin{tabular}{|c|} 
Dicc. Historia \\
Eclesiástica \\
(1972)
\end{tabular} & $\begin{array}{c}\text { C. Derecho } \\
\text { Canónico } \\
\text { (1983) }\end{array}$ & \begin{tabular}{|c|} 
Dicc. \\
Patrimonio \\
Cultural \\
(1991)
\end{tabular} & $\begin{array}{c}\text { Asociación } \\
\text { Archiveros } \\
\text { de la lglesia } \\
\text { (1997) }\end{array}$ & $\begin{array}{c}\text { Manual de } \\
\text { Archivos } \\
(1999)\end{array}$ \\
\hline Diocesano & Diocesano & & Diocesano & Diocesano & Diocesano & Diocesano \\
\hline Catedral & Catedral & Catedral & Catedral & Catedral & Catedral & Catedral \\
\hline Parroquial & Parroquial & Parroquial & Parroquial & Parroquial & Parroquial & Parroquial \\
\hline \multicolumn{7}{|l|}{ Histórico } \\
\hline Secreto & & & Secreto & Secreto & & \\
\hline Colegiata & & & Colegiata & Colegiata & & \\
\hline \multirow[t]{9}{*}{ Fundaciones } & Fundaciones & & & & & \\
\hline & Monacal & Monacal & & & Monacal & Monacal \\
\hline & & Vaticano & & & & \\
\hline & & Seminario & & & & Seminario \\
\hline & & \begin{tabular}{|l|} 
Santa \\
Cruzada \\
\end{tabular} & & & & \\
\hline & & & & C. Episcopal & & \\
\hline & & & & & Hospitales & \\
\hline & & & & & Asoc. fieles & \\
\hline & & & & & & Órd. activa \\
\hline
\end{tabular}




\section{LOS ARCHIVOS DIOCESANOS: APROXIMACIÓN A SU HISTORIA}

En líneas generales, los archivos diocesanos o episcopales son aquellos que custodian la documentación generada por el obispo y su curia en el desarrollo de las múltiples actividades que les han sido asignadas. Su datación se sitúa hacia el siglo XVI, muy estrechamente ligada a las cláusulas emanadas del Concilio de Trento (1545-1563), en las que se dispone la observancia de residencia obispal obligatoria. A pesar de su tardío nacimiento y de los avatares a los que tuvieron que enfrentarse hasta su consolidación (hasta dicho momento, la documentación diocesana era ubicada junto al fondo catedralicio como consecuencia directa de que el obispo formaba parte del cabildo y de la propia inexistencia de archivos diocesanos), los archivos episcopales han destacado por su volumen y riqueza documental dando lugar a una interesantísima producción bibliográfica que permite el análisis pormenorizado de un variado conjunto de aspectos relacionados con estas entidades.

En primer lugar, al referirnos a los archivos diocesanos observamos cómo, de un modo más acusado que en otros estadios de la archivística eclesiástica, la bibliografía diocesana se torna práctica, en tanto que la mayoría de sus fuentes son análisis de casos particulares. Sin embargo, debido al gran volumen de estudios existentes y en contraposición al espacio limitado con el que contamos, nos vemos obligados a exponer sólo aquellos que consideramos más significativos. Tras el análisis de los mismos podemos entrever dos grandes líneas de producción bibliográfica.

Por una parte encontramos instrumentos de descripción y comentarios. El grueso de la producción bibliográfica en archivos diocesanos lo integran, por un lado, los catálogos, ${ }^{8}$ en los que se presentan y describen individualmente el conjunto de elementos que configuran el archivo; por el otro están las guías, que exponen una visión general de los aspectos relevantes, ${ }^{9}$ y después están también los inventarios, ${ }^{10}$ en los que se nos expone una relación detallada que describe las unidades de un fondo; sigue luego su organización en series documentales.

8 Véase J. M. Fernández Catón, Catálogo del Archivo Histórico Diocesano de León; A. Hevia Ballina, Catálogo del Archivo Histórico Diocesano; J. Sales e I. Ursúa, Catálogo del Archivo Diocesano de Pamplona.

9 Véase S. Domato Búa, Archivo Histórico Diocesano. Guía del Visitante; A. Hevia Ballina, Guía del Archivo Histórico Diocesano; J. M. Marqués Planaguma, Arxiu Diocesà de Girona: guia-inventari; J. Melgares, Archivo Histórico Diocesano de Jaén; V. Monachino et al., Guida degli archivi diocesani d'Italia; D. Pérez, Guía del Archivo Diocesano de Cuenca.

10 Véase A. Díaz García, Archivo Diocesano de Albacete. Inventario y Microfilm; S. Domato Búa, Archivo Histórico Diocesano de Santiago de Compostela. Inventario del Fondo General; P. Rubio Merino, "Inventario del Archivo Diocesano de Coria-Cáceres"; M. Vaquerizo, Inventario de libros del Archivo Diocesano de Santander. 
Por otro lado, accedemos a una importantísima y voluminosa bibliografía de carácter general que aborda variopintos aspectos. Así encontramos estudios que exponen los aspectos generales del archivo, ${ }^{11}$ los cuales nos permiten conocer la entidad archivístico-diocesana desde diversas perspectivas: actividades, ${ }^{12}$ etapas, futuro ${ }^{13}$ y trabajos que se centran en el análisis pormenorizado de la documentación diocesana ${ }^{14}$ y nos permiten acceder a una documentación única.

Al día de hoy, uno de los puntos más relevantes en esta materia y que a la vez está generando un volumen documental sumamente interesante es el que se dedica a la integración de los fondos en un Sistema Archivístico. Dichos intentos de globalización documental están ocasionando numerosas investigaciones. Algunas, como las desarrolladas en Castilla y León, Bilbao o Barcelona son claros ejemplos a seguir. A. Barroso, ${ }^{15}$ en su trabajo para la diócesis de Bilbao, muestra las etapas necesarias para el desarrollo del proyecto. Por su parte, Hernández Olivera expone en su estudio para Castilla y León la necesidad de integrar los archivos episcopales en un Sistema Archivístico que permita un desarrollo integral. ${ }^{16}$ Lo mismo ocurre en el caso catalán ${ }^{17}$ en el que los investigadores trabajan en el desarrollo de un sistema integral para la gestión de archivos en la diócesis de Barcelona.

Como ya hemos señalado, los archivos diocesanos son las entidades que albergan la documentación producida por el obispo y su curia en el gobierno diario de su diócesis. El obispo, como prelado superior de una diócesis, tiene bajo su cargo el cuidado espiritual, la dirección y el gobierno eclesiástico de los diocesanos. Ejerce su mandato en un territorio en el que tiene jurisdicción y para ello es asistido por unos colaboradores, que son el vicario, el provisor y el juez eclesiástico. Las actividades que acometen se pueden dividir en tres grandes grupos: administración, gobierno y justicia. De manera breve pode-

11 Véase M. Casares, Memoria de los Archivos diocesanos; M. González, Archivo Diocesano de Astorga. Memoria; J. L. Salestirapu, El Archivo Diocesano de Pamplona.

12 Véase A. García Conde, El Archivo Diocesano de Lugo. Sondeo Documental; A. Quintana, Memoria de actividades del Archivo Diocesano de Astorga.

13 Véase J. M. Marqués Planaguma, Arxiu Diocesa de Girona. Una etapa: llindar de Modest Prat.

14 Véase A. Díaz García, "Archivo Diocesano Concentrado: la experiencia de Albacete"; J. M. Fernández Fernández, "Los fondos del Archivo Diocesano de Mondoñedo"; A. Floristan, "Fondos del Archivo Diocesano para el estudio de la Edad Media"; A. Gil Domínguez, "Historia del Archivo Diocesano de Zaragoza"; M. A. Jaramillo, "Documentación sobre órdenes religiosas en los Archivos Diocesanos"; J. Llanos, "Sistemas archivísticos y gestión de documentos"; J. Roselló Lliteras, Tipología Documental del Archivo Diocesano de Mallorca; P. Rubio Merino, "La documentación Moderna en los Archivos Diocesanos"; M. Sáez de Ocariz y Ruiz de Azúa, "El Archivo Diocesano de Logroño".

15 Véase A. Barroso Arahuetes, "Gestión Integral de Archivos en la diócesis de Bilbao"; "El sistema archivístico para la diócesis de Bilbao".

16 Véase L. Hernández Olivera, "Integración de los Archivos Eclesiásticos en el Sistema de Archivos de Castilla y León".

17 Véase R. Alberch, C. Martínez y X. Tarraubella, "Análisis y diseño de sistemas de gestión integral de archivos. El proceso de elaboración del sistema AIDA en el Ayuntamiento de Barcelona". 
mos señalar que las tareas de administración son las dedicadas a la gestión de sus bienes, los de la mitra y los del obispado (contiene documentos de mitra, patrimonio diocesano, colecturía, capellanías, obras pías, el priorato de ermitas, padrones parroquiales, etc.). Por su parte, las actividades de gobierno son las relacionadas con la gestión diaria del obispado (la cual contiene la secretaría particular del prelado y la secretaría general del obispado, dentro de la cual están también las siguientes series: registro de personal, expedientes de órdenes, cabildo catedral, patronatos y capellanías, hermandades o cofradías y clero regular). Por último, las competencias de justicia son procedimientos relacionados con la administración de la justicia dentro del territorio (recoge pleitos matrimoniales, asuntos matrimoniales y autos apelados).

Continuemos con la historia de estos archivos y para ello trasladémonos al Concilio de Trento (1545-1563). Entre otras cuestiones éste fue motivado por la relajación disciplinar que afectaba a la clerecía del momento, una cuestión que nos interesa sobremanera si nos referimos específicamente a los obispos. Hasta ese entonces, los prelados no residían en las diócesis encomendadas sino en otras, donde obtenían mayores beneficios, y además podían estar al frente de varias diócesis (pluralismo) e incluso ocupando puestos de alta responsabilidad (absentismo). En este sentido, la problemática de residencia de los obispos no era cuestión sencilla, por eso durante el desarrollo del concilio se trató con mucho interés el Ius Divinum. ${ }^{18} \mathrm{Al}$ principio, se pensó en imponer multas a los obispos que estuvieran en esta situación, pero la idea no llegó a ser aprobada. Tal grado alcanzó el conflicto, que en abril de 1562 se originó una grave crisis en Trento y el concilio se paralizó durante un tiempo. Luego, pasados unos meses, comenzaron a discutir las cuestiones referidas al sacramento del orden y reapareció la idea del Ius Divinum. Viendo los padres conciliares que la solución lejos de ser hallada seguía complicándose, decidieron aprobar el deber de residencia de los obispos sin tener en cuenta el Ius Divinum.

Por tanto, es a partir de 1563 que el monarca español Felipe II, por medio de la Real Provisión de 12 de julio de 1563, manda cumplir en la monarquía hispánica las cláusulas acordadas en Trento y, en consecuencia, los obispos son obligados a residir en las diócesis asignadas. En ese momento fijamos el nacimiento de los archivos episcopales ${ }^{19}$ como consecuencia directa de la aplicación de dicha ley.

Los años que siguen al Concilio de Trento fueron de cierta estabilidad en el terreno de la archivística eclesiástica general. Las pautas tridentinas se aplicaron y los archivos episcopales, como el resto, fueron afianzándose.

18 Véase L. Arguello, Manual de Derecho Romano. Historia e Instituciones.

19 Aldea Vaquero, Marín Martínez y Vives Gatell, op. cit., pp. 127-141. 
Debemos esperar hasta el primer cuarto del siglo XVIII para hacer mención de un hecho que tuvo gran repercusión en el panorama de la Iglesia católica y, en particular, en la archivística episcopal. Nos referimos a la Constitución Máxima Vigilantia, aprobada el 14 de junio de 1724 por el entonces papa Benedicto XIII. En líneas generales, se formuló con el propósito de organizar los archivos de la Iglesia a escala universal y sus disposiciones se dirigían especialmente a los archivos diocesanos, aunque indirectamente fueron aplicadas al resto. De la estructura de la citada constitución destacaremos especialmente su sexto capítulo por recoger de forma precisa las cuestiones archivísticas. Los puntos que analiza son los siguientes:

- Creación de inventarios y de catálogos que recopilen el conjunto de la documentación contenida en cada archivo. Deberán ser llevados a término por el encargado del archivo y custodiados por él en la entidad. Su revisión será periódica e implementará la nueva documentación que será incorporada según los periodos que marca la archivística eclesiástica.

- El carácter de la documentación concentrada en los archivos eclesiásticos será de naturaleza privada.

- Existirá la obligatoriedad de constituir en cada archivo un archivo secreto o al menos la existencia de un fondo restringido cuyo contenido será conocido exclusivamente por el archivero diocesano y el obispo. En él se ubicarán aquellos documentos que por su contenido o por su datación requieran ser preservados de la consulta pública.

- Se determina que el sacerdote encargado de cada archivo eclesiástico deberá recibir al menos una formación básica en materia archivística que le permita salvaguardar la documentación encomendada, como garante de la historia de la Iglesia. Hasta ese entonces no era obligatorio que el archivero diocesano tuviera formación alguna en estas materias, hecho que ha dado lugar a importantes dificultades en la conservación documental, pero es a partir de ese momento que la Iglesia católica comprende y pone de manifiesto que las personas que estén encargadas de sus archivos deben poseer una formación archivística ${ }^{20}$ que les permita actuar conforme a pautas preestablecidas.

Los archivos diocesanos, como el resto de los archivos eclesiásticos, siguieron consolidándose en el tiempo. En líneas generales fueron bien conservados por los archiveros eclesiásticos y se cumplió con los preceptos que 
la Iglesia católica iba fijando para la salvaguarda documental. Sin embargo, a mediados del siglo XIX empezaron a desaparecer algunos documentos de sus fondos, a lo que hay que añadir los posteriores conflictos civiles que mermaron aún más la documentación de muchos de estos archivos. Las desamortizaciones también supusieron para la Iglesia católica la pérdida de muchos de sus bienes. El patrimonio documental no se vio libre de estos conflictos. Muchos documentos contenidos en los archivos, así como libros de las bibliotecas, desaparecieron para siempre.

El paso del tiempo nos muestra cómo los archiveros eclesiásticos han ido orientando sus esfuerzos hacia la consecución de un Sistema Archivístico Diocesano. En primer lugar, serán las propias iglesias las que velen en pro de la memoria histórica, pero de una forma más directa el Código de Derecho Canónico de 1983 impone al obispo la obligación de estar atento para que:

[...] las actas y documentos de los archivos de las iglesias catedralicias, colegiatas, parroquias y de otras iglesias de su territorio se conserven diligentemente y que se compilen los inventarios o índices en dos ejemplares, de los cuales uno se conserve en el propio archivo y el otro en el archivo diocesano. ${ }^{21}$

Es importante señalar que el archivo histórico diocesano no se concibió en el esquema que en 1977 se preparó para la modificación, ampliación y renovación del Código de Derecho Canónico de 1917, sino que fue introducido en un borrador posterior que se dio a conocer el 15 de abril de 1980. Es, por tanto, la consecución del Archivo Histórico Diocesano el punto central en el panorama actual de estas entidades.

No cabe duda que estos procesos, asentados y consolidados desde hace años en la archivística civil, han llegado más tarde al mundo archivístico eclesiástico, pero también cabe resaltar el considerable esfuerzo que los archiveros eclesiásticos fueron desempeñando para adecuarse a esa realidad e incorporarla en sus archivos.

Propuesta de CUADRo de ClasificaCión PARA los ARChivos diocesanos

Desde el punto de vista archivístico, el cuadro de clasificación es el instrumento técnico que refleja la estructura de un archivo con base en las atribuciones y funciones de cada dependencia o entidad productora de los documentos, y que se fundamenta en las estructuras y jerarquías administrativas 
de la institución con base en el organigrama funcional de ésta. La organización de los documentos se realiza de acuerdo con el mismo orden con el que se dividen y subdividen las diversas dependencias del organismo de procedencia hasta llegar a su grado inferior, respetando el principio de procedencia: cada documento debe estar colocado en el fondo del que proviene, y en ese fondo en su lugar de origen; es decir, se conservará el orden establecido por la persona física o moral que creó los documentos.

Siguiendo estas premisas aplicables al conjunto de archivos (civiles y/o eclesiásticos), las cuales nos obligan a conocer previamente la estructura de la entidad generadora de la documentación, hemos esbozado el siguiente cuadro de clasificación que, en líneas generales, puede ser aplicado al conjunto de archivos diocesanos que constituyen la Iglesia católica. Como tal, se trata de un hipotético cuadro de clasificación, de carácter funcional, genérico y no específico de un archivo, que servirá para el conjunto de archivos diocesanos y que será adaptado en cada caso según las particularidades propias de cada entidad.

Tabla II. Propuesta de cuadro de clasificación para archivos diocesanos

\begin{tabular}{|c|c|c|}
\hline \multicolumn{3}{|c|}{ Propuesta de cuadro de clasificación para archivos diocesanos } \\
\hline \multicolumn{3}{|c|}{ Secciones } \\
\hline 1. Administración & 2. Gobierno & 3. Justicia \\
\hline \multicolumn{3}{|c|}{ Series } \\
\hline $\begin{array}{l}\text { 1.1 Colecturía } \\
\text { 1.1.1 Diezmos } \\
\text { 1.1.2 Primicias }\end{array}$ & $\begin{array}{l}\text { 2.1 Capellanías y obras pías } \\
\text { 2.1.1 Dotaciones } \\
\text { 2.1.2 Fundaciones } \\
\text { 2.1.3 Nombramientos } \\
\text { 2.1.4 Renuncias } \\
\text { 2.1.5 Testamentos }\end{array}$ & $\begin{array}{l}\text { 3.1 Autos apelados } \\
\text { 3.1.1 Registro de autos apelados }\end{array}$ \\
\hline $\begin{array}{l}\text { 1.2 Mitra } \\
\text { 1.2.1 Censos } \\
\text { 1.2.2 Cuentas de fábrica }\end{array}$ & $\begin{array}{l}\text { 2.2 Clero regular: convento } \\
\text { 2.2.1 Cargos } \\
\text { 2.2.2 Elecciones } \\
\text { 2.2.3 Informes } \\
\text { 2.2.4 Nombramientos y ceses } \\
\text { 2.2.5 Secularizaciones } \\
\quad \text { conventuales } \\
\text { 2.2.6 Visitas }\end{array}$ & \begin{tabular}{|l|} 
3.2 Matrimonios \\
3.2.1 Anulaciones \\
3.2.2 Dispensas
\end{tabular} \\
\hline $\begin{array}{l}\text { 1.3 Padrones parroquiales } \\
\text { 1.3.1 Padrones }\end{array}$ & $\begin{array}{l}\text { 2.3 Hermandades y cofradías } \\
\text { 2.3.1 Acuerdos } \\
\text { 2.3.2 Elecciones } \\
\text { 2.3.3 Inventario de bienes } \\
\text { 2.3.4 Nombramientos }\end{array}$ & $\begin{array}{l}\text { 3.3 Pleitos civiles } \\
\text { 3.3.1 Expedientes de pleitos } \\
\text { civiles }\end{array}$ \\
\hline $\begin{array}{l}\text { 1.4 Priorato de ermitas } \\
\text { 1.4.1 Estadísticas } \\
\text { 1.4.2 Fundaciones } \\
\text { 1.4.3 Reparaciones }\end{array}$ & $\begin{array}{l}\text { 2.4 Órdenes } \\
\text { 2.4.1 Nombramientos } \\
\text { 2.4.2 Secularizaciones }\end{array}$ & $\begin{array}{l}\text { 3.4 Pleitos criminales } \\
\text { 3.4.1 Expedientes de pleitos } \\
\text { criminales }\end{array}$ \\
\hline
\end{tabular}




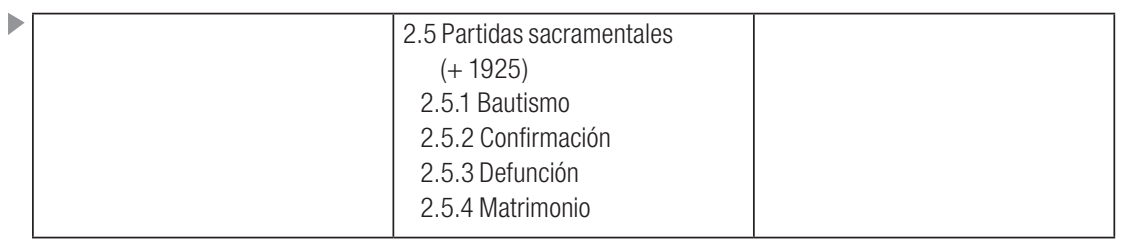

\section{ANÁLISIS DE SERIES DOCUMENTALES}

Procederemos ahora a desgranar el hipotético cuadro de clasificación que hemos diseñado para el conjunto de archivos diocesanos o episcopales que constituyen la Iglesia católica y analizaremos cada una de las secciones y series documentales que los componen, con base en las funciones y actividades que han generado históricamente la documentación.

\section{Administración}

Esta sección se relaciona con las actividades encaminadas a la gestión de los bienes del obispo, los de la mitra y los del obispado. Se encuentra dividida en cuatro subsecciones.

\section{Primera subsección. Colecturia (1.1)}

Abarca las funciones encaminadas a la gestión específica de las limosnas. Está integrada por dos series: diezmos y primicias.

- Diezmos (1.1.1). Documentación en la que se refleja el pago, generalmente una décima parte de la cosecha, que desde antaño se vino dando a la Iglesia católica. Era por tanto un impuesto o tributo establecido en la sociedad eclesiástica que satisfacían los fieles, y que consistía en una porción de los frutos de sus propios bienes o industria que entregaban a la sociedad eclesial para el sostenimiento de las cargas públicas de la misma. Tanto los diezmos como las primicias constituían un modo de adquirir o eran la fuente patrimonial del derecho público que tenía la Iglesia. Su entidad jurídica se traducía en una obligación para los fieles.

El momento histórico culminante de la institución lo situamos en los siglos XI-XIII, cuyo ambiente incluía una impronta socio-jurídica de confusión de la propiedad territorial y de la soberanía política, donde el diezmo o tributo que el dominus, el soberano, percibía de los 
frutos del campo quedaba impreciso en lo referente a su naturaleza jurídica. La propiedad había sido, en derecho romano, una simple relación de derecho privado, pero en la alta Edad Media europea se había convertido en la primera institución del derecho público. ${ }^{22}$

Los diezmos llamados eclesiásticos eran de dos tipos: prediales (recaudados de los frutos de la tierra) y, en cuanto a su extensión real, se percibían del producto bruto; en cambio los llamados personales (obtenidos de las rentas laborales y caídos en desuso en 1500) se liquidaban después de descontar los gastos de producción; es decir, sobre la renta neta.

Centrándonos en la documentación diezmal, ¿por qué se custodia está documentación en los archivos diocesanos? Porque los obispados eran los máximos responsables en hacer que dicho pago se cumpliera en cada una de sus diócesis.

- Primicias (1.1.2). Documentación generada por las prestaciones de frutos o ganados que, además de los diezmos, debían ser cedidas a la Iglesia católica. En el cristianismo, la primicia pasó a ser una parte voluntaria que se ofrecía a Dios, la primera entre todas y, con el tiempo, al inicio de la Edad Media, como un tributo obligatorio que constituía un auténtico impuesto incorporado a los beneficios eclesiásticos, como el diezmo, siendo una figura de recaudación fundamental para la Iglesia católica hasta bien entrado el siglo XIX. ${ }^{23}$

Como en el caso anterior, el obispado como máximo órgano eclesiástico de la diócesis custodiaba la documentación que acreditaba el pago de este tributo como garantía del mismo, y por ello la documentación se salvaguardó en estos archivos.

Segunda subsección. Mitra (1.2)

Está integrada por el conjunto de actividades cuyo fin era la gestión de la fábrica del obispado, que aunque menor que la catedralicia tenía una gran importancia. Las series documentales que la constituían eran dos: censos y cuentas de fábrica.

- Censos (1.2.1). Dentro de la economía agraria de España las tierras estaban gravadas por una serie de rentas que se llamaban censos. Éstos, pagados en especie, sirvieron de sustento tanto a la monarquía como 
a la Iglesia católica. La documentación sobre censos es voluminosa en los archivos diocesanos dado que la Iglesia, a lo largo de los tiempos, fue beneficiada por muchos de ellos.

- Cuentas de fábrica (1.2.2). Documentación en la que se enumeraban los gastos que habían supuesto exclusivamente las reparaciones efectuadas en la fábrica del obispado.

Tercera subsección. Padrones parroquiales (1.3)

Recogía los datos de las parroquias que integraban la diócesis. Estaba integrada por la serie documental Padrones (1.3.1), que era de gran utilidad para hacer sondeos estadísticos sobre fieles, actividades o índices de participación. Una vez más el obispado aparece como el coordinador que asumía tareas de control y de ahí la existencia de dicha documentación en sus archivos. Por tanto era una documentación que recibía -no que se generaba- en las parroquias en el transcurso de su funcionamiento diario.

\section{Cuarta subsección. Priorato de ermitas (1.4)}

Estaba relacionada con la gestión de las ermitas, santuarios o capillas de pequeño tamaño existentes o que habían existido en una diócesis, y que no tenían culto permanente. La persona encargada de su gestión controlaba las cuentas de ermitas autorizando gastos de obras y reparaciones, designaba al ermitaño encargado del cuidado, etc. Por haber desaparecido muchas de las ermitas sus libros y legajos se ubican ahora en los archivos diocesanos. Está subsección está integrada por las tres series documentales siguientes:

- Estadísticas (1.4.1). Documentación de carácter puramente cuantitativo que se refería al número de actos y participación en dichas entidades.

- Fundaciones (1.4.2). Actas de erección de ermitas en la jurisdicción de ese obispado. Es una documentación que en muchos casos se convertía en garante jurídico de la fundación cuando no existían otros documentos que así lo acreditaran. En ermitas desaparecidas son documentos únicos.

- Reparaciones (1.4.3). Documentación referente a modificaciones estructurales efectuadas exclusivamente en ermitas. Esta documentación se custodia en los archivos diocesanos porque el obispado era la entidad que abonaba o financiaba dichas modificaciones dado que las ermitas solían carecer de fondos propios. 


\section{Gobierno}

Esta sección estaba relacionada con la gestión de cada uno de los aspectos constitutivos del obispado y se correspondía directamente con la función gubernativa del máximo prelado de la diócesis, el obispo. Era por tanto de singular importancia en el cuadro de clasificación dado que se correspondía directamente con el organigrama de la entidad. Estaba dividida en cinco subsecciones.

\section{Primera subsección. Capellanias y obras pias (2.1)}

Estaba constituida por aquella documentación en la que una persona hacía entrega de un número de bienes determinados a la Iglesia para ser empleados en un fin piadoso.

Fundamentalmente eran obras pías instauradas en la Iglesia católica mediante las cuales el fundador, generalmente una persona acaudalada, dejaba en su testamento una cantidad de dinero que se ponía en renta, para que con las ganancias se pagara la realización de un número determinado de misas para la salvación de su alma. De origen medieval, las capellanías tuvieron gran auge en España, Portugal y sus reinos en América durante los siglos XVI, XVII y XVIII. En esto tuvo mucho que ver la cultura del barroco que hizo énfasis en la muerte, el Purgatorio y la salvación del alma. Este procedimiento, que llegó a ser muy común en otras épocas, generó grandes beneficios como atestiguan los documentos custodiados en archivos eclesiásticos. Los obispados, en gran medida, fueron beneficiados en este tipo de procesos. Podemos establecer cinco series documentales, que se detallan a continuación.

- Dotaciones (2.1.1). Documentación en la que se especificaban los bienes con los que se iba a dotar una capellanía, así como las cargas que se asociaban a la misma; obligación de misas o asistencia a las horas canónicas. Es por tanto una memoria en la que el fundador de la capellanía desgranaba punto por punto los aspectos constitutivos de la dotación.

- Fundaciones (2.1.2). Actas fundacionales y cargas pías de las capellanías.

- Nombramientos (2.1.3). Documentación sobre elecciones de capellanes motivadas por la erección de la misma o por vacancia del puesto. El capellán servía a la capellanía levantando las cargas, como la celebración de matrimonios, el número de misas en fiestas particulares, otra institución benéfica, e incluso prestando su trabajo religioso al servicio de personajes de la nobleza o de la alta sociedad. 
- Renuncias (2.1.4). Expedientes de renuncia de capellanes en las que se indicaban los motivos por los que se llevaba a término tal situación.

- Testamentos (2.1.5). Disposiciones de últimas voluntades en las que el testador ordenaba lo referente a sus bienes tras su muerte. El testamento solía contener una designación de bienes, mandas o donativos con indicación de sus beneficiarios, los cuales solían ser hijos, parientes, extraños y la Iglesia, muy beneficiada en ciertos momentos.

Segunda subsección. Clero regular: convento (2.2)

Daba cabida a la documentación que surgía de las comunicaciones entre el obispado y los conventos que tenía bajo su jurisdicción en la diócesis.

El clero regular, del latín regula (que significa "regla"), se refiere al fraile o sacerdote que vivía en conventos bajo las reglas determinadas por la orden. A este grupo pertenecían las órdenes mendicantes y otras que también tenían reglas en común. El superior de la orden o de la casa era a quien se le debía obediencia. El superior general era la autoridad máxima, quien a su vez dependía directamente de la autoridad del papa. Las comunicaciones eran constantes, prueba de ello es la riqueza y variedad de esta subsección. Se integra por las seis series documentales siguientes.

- Cargos (2.2.1). Documentación relativa a la toma de cargos en un convento, especialmente los referidos al prior, guardián, abad en conventos masculinos y priora, guardiana o abadesa en femeninos. La designación de nuevos cargos dentro de la estructura conventual debía ser comunicada al obispo para dar fe de la misma.

- Elecciones (2.2.2). Procesos selectivos en los conventos. El obispo enviaba a un vicario u otro emisario de su entorno para que asistiera y diera fe de los procesos electorales que se llevaban a término en los conventos de su diócesis por medio de los cuales se renovaba la "dirección conventual”. Cada orden religiosa establecía su propia periodización para el desarrollo de ese proceso (generalmente cuatro años), además y por renuncia del cargo anterior, las elecciones conventuales podían desarrollarse fuera de los marcos establecidos en las reglas y constituciones de cada orden. Se trataba de una votación en la que cada uno de los miembros de la comunidad conventual votaba al candidato o candidata que considerara más oportuno para el gobierno del convento. La documentación llegaba a los archivos episcopales como prueba del desarrollo de esos procesos. El obispo no participaba del 
mismo, sino que validaba su desarrollo y resolución. Por ello, debía conservar dicho documento en sus archivos.

- Informes (2.2.3). Documentación de variada naturaleza y volumen en la que se daban a conocer todo tipo de vivencias y sucesos conventuales. Son verdaderos diarios de las entidades conventuales y nos permiten conocer su funcionamiento diario así como situaciones excepcionales.

- Nombramientos y ceses (2.2.4). Documentación relativa a la toma de cargos asignados en procesos electorales, así como al cese en el desempeño de otras tareas.

- Secularizaciones conventuales (2.2.5). Informes en los que un religioso se alejaba de la vida sagrada así como de las posiciones dogmáticas para emprender una vida fuera del convento y de la Iglesia católica. El expediente secularizador debía ser validado en el obispado, de ahí que aparezca documentación de esta naturaleza en los archivos diocesanos. Una vez más el obispado actuaba como garante de procesos conventuales.

Los expedientes secularizadores llegaron a ser sumamente abundantes en el primer tercio del siglo XIX, cuando las desamortizaciones hicieron que muchos religiosos y religiosas se alejaran de la vida conventual; de ello dan fe los documentos custodiados en los archivos episcopales. Su estructura es homogénea, después de que el solicitante exponía sus datos personales, orden y entidad conventual a la que pertenecía debía exponer en unas líneas los motivos que lo llevaban a la petición secularizadora explicando detalladamente cada uno de ellos. Al final, el solicitante exponía el tipo de secularización que solicitaba: temporal, si se trataba de una secularización reversible en la que los deseos lo llevaban a querer retomar la vida conventual tras un tiempo fuera de la clausura, o perpetua, en la que el solicitante quería alejarse para siempre de la conventualidad y orden a la que pertenecía.

- Visitas (2.2.6). Informe de las visitas periódicas que el obispo o alguno de sus emisarios, generalmente el vicario general, efectuaban a los conventos para observar su funcionamiento conforme a las reglas establecidas.

\section{Tercera subsección. Hermandades y cofradías (2.3)}

Daba cabida a los documentos sobre entidades de este tipo que tenían su sede en conventos. Una cofradía o hermandad era una asociación de fieles católicos, pública o privada, establecida conforme a los cánones del Título 
V del Código de Derecho Canónico. El órgano plenario de la cofradía era el cabildo o asamblea general. El cabildo general era el encargado de elegir a la Junta de Oficiales o de Gobierno, que era el órgano permanente de dirección de la cofradía y estaba encabezado por su Presidente, Hermano Mayor o Padre Mayor.

Antiguamente fueron advocaciones con finalidades gremiales, profesionales e incluso institucionales. Su estructura más desarrollada contaba con un Hermano Mayor, cargo supremo de la entidad al que se accedía mediante elección; un Teniente de Hermano Mayor, encargado de suplir al Hermano Mayor; los mayordomos, que llevaban la administración de la economía de la Hermandad, y los Consiliarios o Fiscales, que estaban encargados de hacer cumplir las reglas. Los Secretarios se responsabilizaban de escribir las actas de cabildos y comunicados oficiales; los Priostes montaban, desmontaban y cuidaban todos los aspectos de decoración y cuidado de las imágenes y andas; los Diputados; el Capillero, cuya ocupación era la de abrir y cerrar la sede de la Hermandad, y cuidar y vigilar el edificio cuando era propio de la Cofradía. El resto de los Hermanos estaban dotados de voz y voto asambleario.

Todos los cargos eran renovados con periodicidad, normalmente cada cuatro años. La gestión de la cofradía se regía de manera colegiada mediante cabildos que, atendiendo al número de convocados, se calificaban en Generales (cuando concurrían la totalidad de los hermanos) y de Oficiales (reservados para la Junta de Gobierno). Las autoridades espirituales impusieron la adopción de unos estatutos que regulaban su vida interna, refrendando o corrigiendo las ordenanzas redactadas por sus rectores que habían sido aprobadas en cabildo general. Dicho documento se denominaba Reglas y Ordenanzas, más conocidas como "las reglas".

Esta subsección se dividía en cuatro series documentales para cada una de las cofradías y hermandades que existían.

- Acuerdos (2.3.1). Documentación relativa a las asambleas que de forma periódica realizaban estas entidades con el fin de su buen funcionamiento.

- Elecciones (2.3.2). Documentación relacionada con procesos electivos.

- Inventario de bienes (2.3.3). Relación de posesiones que ostentaban cofradías y hermandades. En algunos casos son de gran importancia.

- Nombramientos (2.3.4). Documentación generada en los procesos en que estas entidades imponían nuevos cargos y tareas a sus miembros. 


\section{Cuarta subsección. Órdenes (2.4)}

Estaba compuesta por los documentos que versaban sobre la imposición del séptimo sacramento de la Iglesia. Veamos en qué consistía este proceso para comprender mejor la documentación que va a constituir esta subsección.

El orden sagrado ${ }^{24}$ era uno de los sacramentos de la Iglesia católica. Consistía en la consagración de un varón al ministerio del servicio a la Iglesia, lo que le exigía dedicación plena y libre disposición: toda persona consagrada, adquiriera o no la plenitud de orden, llevaba una vida sacerdotal. El crecimiento de la Iglesia hizo necesaria la llamada de otros que vinieran a ayudar en el servicio de la mesa, en la predicación y en la celebración eucarística. Tres eran las funciones principales del sacerdote: predicación, celebración de los sacramentos y gobierno pastoral.

La documentación que se custodia en los archivos diocesanos tenía que ver precisamente con este paso de recepción del orden sacerdotal, porque no olvidemos que el obispo era quien impartía dicho sacramento y a su vez se convertía en garante del mismo. Esta documentación se presentaba divida en dos grandes series:

- Nombramientos (2.4.1). Documentación requerida para la obtención del grado sacerdotal. Se trataba de una documentación específica para cada postulante al orden en la que se incluían ciertos documentos que constituían cada expediente personal: partida bautismal, certificación académica de estudios teológicos, documento acreditativo de conducta y otros informes expedidos en los seminarios que daban fe y testimoniaban el paso del futuro sacerdote por la vida previa a la recepción del sacramento del orden. Esta documentación concluía con el acta de la recepción del sacramento que era emitida por el obispo y validada por el canciller.

- Secularizaciones (2.4.2). Documentación que se generaba del proceso en el que un sacerdote era reducido a su estado laical con dispensa de sus votos, y que autorizaba a un religioso para que viviera fuera de la clausura.

El expediente secularizador no difería de los ya expuestos para los casos secularizadores del clero regular. Por tanto, se componía de una primera parte dedicada a los datos del solicitante y otra en la que los motivos que lo llevaban a la petición secularizadora eran explicados detalladamente cada uno. 
El expediente secularizador era validado en el obispado y a ello se debe que aparezca documentación de esta naturaleza en los archivos diocesanos. Una vez más el obispado actuaba como garante de los procesos eclesiásticos.

Quinta subsección. Partidas sacramentales (2.5)

Está integrada por las copias de las partidas a partir de 1925, según establecía el Código de Derecho Canónico, fecha en la que se hacía obligatorio el envío de las copias de las parroquias a los obispados. El código establecía previamente que:

[en] cada parroquia se han de llevar los libros parroquiales, es decir, de bautizados, de matrimonios y de difuntos, y aquellos otros prescritos por la Conferencia Episcopal o por el obispo diocesano. Cuide el párroco de que esos libros se anoten con exactitud y se guarden diligentemente $\left[\ldots .{ }^{25}\right.$

Aparece dividida en cuatro series documentales:

- Bautismos (2.5.1). Copia de las partidas de todos los individuos que recibieron este sacramento.

- Confirmaciones (2.5.2). Copia de los expedientes de confirmados.

- Defunciones (2.5.3). Expedientes de finados.

- Matrimonios (2.5.4). Copia de los expedientes matrimoniales.

\section{Justicia}

Esta sección está relacionada con la administración de la justicia en la diócesis. Dichas tareas daban lugar a cuatro subsecciones.

Primera subsección. Autos apelados (3.1)

Se integraba de una única serie documental, la llamada Registro de autos apelados (3.1.1), en la que se reunían los autos procedentes del Tribunal Metropolitano, es decir, todo lo que se relacionaba con la metrópoli, la ciudad principal o la sede de una provincia eclesiástica.

En la Iglesia católica los tribunales eclesiásticos son organismos jurídicos donde se juzga con derecho propio y exclusivo las causas que se refieren a co- 
sas espirituales, o relacionadas a ellas, así como la violación de las leyes eclesiásticas y todo aquello que contenga razón de pecado, por lo que se refiere a la determinación de la culpa y a la imposición de penas eclesiásticas. ${ }^{26}$

Segunda subsección. Matrimonios (3.2)

Se trataba de la documentación requerida por el obispado para la tramitación de matrimonios que requerían permisos especiales. Estaba constituida por dos series documentales:

- Anulaciones (3.2.1). Expedientes matrimoniales que habían sido dados por nulos o habían dejado de tener validez eclesiástica. Aunque los Tribunales Eclesiásticos podían instruir diversos tipos de causas la mayor parte de su actividad la constituían las causas de nulidad matrimonial. En este tipo de procesos, si la sentencia estimaba lo solicitado en la demanda, se declaraba la nulidad del matrimonio desde el momento de su celebración, es decir, que no había existido vínculo matrimonial.

- Dispensas (3.2.2). Privilegios que eximían de una obligación o permitían hacer algo prohibido. Bajo este aspectos se recogían dispensas de consanguinidad o afinidad.

Tercera subsección. Pleitos civiles (3.3)

Agrupaba los documentos generados por el Juez Eclesiástico en el desarrollo de sus competencias. Dichos pleitos daban lugar a la serie documental Expedientes de pleitos civiles, los cuales versaban sobre diferentes procedimientos.

- Expedientes de pleitos civiles (3.3.1). Podían ser muy variados:

- Herencias: pleitos motivados por motivos de herencias.

- Impagos: pleitos ocasionados por la falta de pago de una deuda al término de su tiempo.

- Reclamaciones: pleitos presentados por protestar contra algo u oponerse a ello.

- Testamentos: pleitos ocasionados por la falta de cumplimiento de la última voluntad. 


\section{Cuarta subsección. Pleitos criminales (3.4)}

Es decir, todos aquellos que habían sido tramitados por la vía penal no civil. Está compuesta por la serie Expedientes de pleitos criminales (3.4.1), los cuales versaban mayoritariamente sobre los siguientes procesos:

- Agresiones: pleitos ocasionados por ataques violentos.

- Amancebamiento: pleitos cuya temática versa sobre personas que vivían en común sin estar casados.

- Deudas: pleitos ocasionados por impagos.

Es, por tanto, la documentación que se custodiaba en los archivos diocesanos o episcopales de variada naturaleza, como podemos observar tras el desarrollo de un hipotético cuadro de clasificación, que nos permite acceder a procesos de singular relevancia para la jurisdicción eclesiástica a la que se circunscribía la diócesis.

\section{PRINCIPALES TEMÁTICAS HISTÓRICAS PARA LA INVESTIGACIÓN EN ARCHIVOS DIOCESANOS}

Los archivos como fuente de investigación histórica y como patrimonio documental serán más valiosos cuanto más antigua sea la institución que los creó y conservó, especialmente si ofrecen una continuidad a lo largo de los años.

En el mundo eclesiástico esta cuestión es obvia y aunque los archivos diocesanos no fueron los primeros en constituirse, dado que no lo hacen hasta mediados del siglo XVI, han mantenido a lo largo de los tiempos un patrimonio documental que así lo atestigua. Son por tanto una herramienta que presta un servicio primordial para la investigación histórica dado que mantienen una cronología uniforme que se vio únicamente fragmentada en la época de las desamortizaciones del siglo XIX.

La investigación histórica que estos archivos nos ofrece puede referirse a multitud de temas, aparte, como es obvio, de los puramente eclesiásticos: relaciones Iglesia-Estado, desamortizaciones, regímenes censales, diezmos, arte, genealogía, sociología, estadística y derecho son simplemente algunos de ellos.

El cuadro de clasificación de los archivos diocesanos expuesto en el apartado anterior representa la complejidad de estas instituciones y las múltiples relaciones que se establecen dentro de las mismas. Como en el caso de los archivos parroquiales, monásticos y catedralicios, los archivos episcopales 
albergan contenidos de suma importancia para la investigación histórica, no exclusivamente de tipo eclesiástico. Nos centraremos en este momento en exponer los contenidos más relevantes y útiles para la investigación.

\section{Genealogía}

Los archivos eclesiásticos, especialmente los parroquiales y diocesanos, conservan las partidas de bautismo, matrimonio y defunción anteriores a 1870 , fecha en la que se creó oficialmente el registro civil en la monarquía hispánica. Por tanto, obtener información de nuestros antepasados anterior a dicha fecha se convierte en una tarea inalcanzable sin recurrir a los archivos eclesiásticos. Éstos albergan documentación desde mediados del siglo XVI, época en la que se comenzaron a consolidar este tipo de archivos.

Aunque oficialmente serían los archivos parroquiales los encargados de custodiar y conservar esta documentación en primera instancia, en muchos países, sirva de ejemplo España, la información contenida en los libros parroquiales es traspasada periódicamente a los archivos diocesanos, situados en la sede del obispado al que pertenece la parroquia. Este hecho es sumamente importante, porque muchas veces en las parroquias se han perdido por diversas razones los libros originales, sin embargo existe una copia de las inscripciones en los archivos diocesanos.

Éstos, por tanto, nos ofrecen esta línea para la investigación histórica. La documentación que en ellos se custodia permite el trazado de la ascendencia o descendencia de una persona, familia o linaje, así como la consecución de árboles genealógicos que de otro modo quedarían incompletos si únicamente recurrimos a la documentación custodiada en archivos civiles.

\section{Arte}

Los archivos eclesiásticos y en particular los diocesanos, que abordamos ahora, son una inmensa fuente documental para el estudio del arte en toda su extensión. El archivo episcopal custodia principalmente documentación artística de otras entidades, especialmente cofradías y hermandades, al tratarse de entidades menores, aunque también es cierto que podemos localizar documentación propia referida al patrimonio artístico del que es poseedor el obispado. No olvidemos que como sede del obispo alberga, en la mayoría de los casos, un patrimonio artístico de considerable valor.

Dejando al margen la documentación artístico-contable, en la que podríamos analizar costos y gastos, destacaremos la documentación sobre patrimonio artístico propiamente dicha, dada su riqueza e interés. Aunque en 
menor medida que en los archivos catedralicios, en los diocesanos localizamos abundante documentación que nos va a facilitar la investigación sobre artistas, piezas pictóricas, orfebrería, escultura, periodos específicos de la historia del arte eclesiástico, etc. Además, es de suma importancia para los investigadores la datación de las piezas. En algunos casos, la documentación contenida en los archivos eclesiásticos es la única herramienta con la que los investigadores cuentan. Las técnicas restauradoras también se verán respaldadas documentalmente en estos archivos dado que los informes de los procesos restauradores forman parte de ellos. Son por tanto los archivos diocesanos fuente fidedigna para la investigación histórico-artística.

\section{Censos}

Los censos aparecen como parte constitutiva de los cuadros de clasificación de los archivos catedralicios, monásticos, parroquiales y diocesanos. En líneas generales, la historia nos muestra cómo, dentro de la economía agraria de España, las tierras estaban gravadas por una serie de rentas que se llamaban censos. Éstos, pagados en especie, sirvieron de sustento tanto a la monarquía como a la Iglesia durante un periodo importante de tiempo.

La documentación sobre censos es realmente significativa y voluminosa en los archivos episcopales dado que la Iglesia, a lo largo de los tiempos, fue beneficiada por muchos de ellos. El estudio de dichos contenidos nos permite acceder a un proceso histórico-económico que en la actualidad carece de la significación que tuvo en épocas pasadas.

\section{Los diezmos y primicias}

La documentación sobre diezmos, como hemos anotado ya, refleja el pago generalmente de una décima parte de la cosecha, que desde antaño se vino haciendo a la Iglesia. Por su parte, la documentación generada por las prestaciones de frutos o ganados que, además de los diezmos, debían ser cedidas a la Iglesia era lo que se conocía como primicias. El obispado como máximo órgano eclesiástico en la diócesis custodia, en sus archivos diocesanos, la documentación que acredita el pago de estos tributos.

$\mathrm{El}$ análisis de estos contenidos ofrece a los investigadores una fuente inagotable de contenidos sobre un proceso histórico-económico que fue sumamente relevante para la historia económica, agraria e institucional de la monarquía hispánica. Las líneas de investigación que se abren mediante el análisis de estos contenidos son por tanto únicas y garantizan el conocimiento exhaustivo de un proceso que fue usual en otras épocas. 


\section{Hermandades y cofradías}

La documentación sobre hermandades y cofradías que se conserva en los archivos diocesanos es de gran utilidad especialmente para aquellas instituciones que no poseen archivos propios. Los diocesanos se convierten en fuente única de testimonio de su historia, en algunos casos de varios siglos de antigüedad. Esta práctica fue habitual en épocas pasadas y prueba de ello es la amplísima documentación que se ubica en los archivos episcopales.

Los contenidos históricos que se ofrecen a los investigadores son variados dado que éstos podrán ver colmados sus intereses artísticos (muchas de estas entidades conservan documentos sobre las tallas que posee la cofradía, algunas de ellas son piezas de singular valor artístico que permiten conocer la historia no sólo de la imagen sino también del escultor, orfebre, bordadores, etc. que los confeccionaron) o patrimoniales (las cofradías y hermandades, como otras entidades religiosas, poseen un patrimonio propio que en muchos casos proviene de testamentos o donaciones). El análisis de esta documentación permitirá conocer datos de singular relevancia tanto desde el punto de vista patrimonial como personal; esto es, el de los grandes benefactores. También encontramos aquí asuntos estructurales vinculados a su documentación interna; es decir, aquellos por los que se erige y desarrolla la hermandad o cofradía. Por último, el análisis de reglamentos o constituciones nos permite ver la evolución de las cofradías a lo largo de los siglos.

\section{Cuestiones conventuales}

Como en el caso anterior, la documentación sobre conventos que se conserva en los archivos diocesanos es de gran utilidad especialmente para aquellas entidades que han desaparecido con el devenir del tiempo. En muchos casos los únicos datos históricos documentables sobre ciertas entidades conventuales sólo pueden ser localizados en los archivos diocesanos (planos, constituciones, patrimonio, etc.). La importancia de esta sección es por tanto palpable en todos estos casos que, especialmente en el siglo XIX, fueron muy abundantes.

\section{Conclusiones}

1. Cabe recordar en primer lugar que los archivos diocesanos o episcopales son los conservadores de una importantísima parte de la cultura de todos los tiempos. Por ello debemos resaltar la necesidad inmi- 
nente de que en todos los archivos que componen la Iglesia católica se efectúen sin más dilación tareas de ordenación y clasificación de sus fondos que no sólo traigan a la luz documentación hasta la fecha inédita, sino que eviten su destrucción; es decir, la lapidación de la historia eclesiástica española.

2. La presentación del cuadro de clasificación expuesto resulta ser también una de nuestras conclusiones. Se trata, como hemos podido ver, de un cuadro funcional, hipotético y erigido con base en tres grandes funciones: administración, gobierno y poder. De esta manera, cada una de las funciones mencionadas queda desarrollada mediante diferentes actividades administrativas que devienen en las diferentes series documentales analizadas.

3. En líneas generales podemos manifestar que los contenidos que yacen en los archivos diocesanos o episcopales serán de gran utilidad para la realización de variados trabajos de investigación. Especialmente, los archivos diocesanos albergan una documentación de suma importancia para la historia del arte dado que en todos sus archivos se conservan documentos que dan fe del trazado de obras artísticas que nos permiten su estudio y conservación futura. La conventualidad española, y de forma particular estos archivos, custodian documentación única de aquellas entidades que a lo largo de los tiempos han desaparecido con los diversos avatares a los que la Iglesia católica se ha enfrentado en su historia. En ocasiones cofradías y hermandades han encontrado en los archivos diocesanos sus propios archivos dado que muchas de estas entidades no poseían o habían poseído archivos propios. Para obtener datos sobre estas primeras agrupaciones (artísticos, patrimoniales, económicos, testamentos, bienes, etc.) que se dilatan siglos atrás es fundamental y también enriquecedor recurrir a estos archivos.

\section{BiBLIOGRAFÍA}

Alberch, R.; C. Martínez y X. Tarraubella, "Análisis y diseño de sistemas de gestión integral de archivos. El proceso de elaboracion del sistema AIDA en el Ayuntamiento de Barcelona”, en Revista Tría, vol. VI, 1999, pp. 83-113.

Aldea Vaquero, Q.; T. Marín Martínez y J. Vives Gatell, Diccionario de Historia Eclesiástica, Madrid: Instituto Enrique Florez, 1972.

Arguello, L., Manual de Derecho Romano. Historia e Instituciones, Buenos Aires: Astrea, 2000. 
Asociación de Archiveros de la Iglesia, Clasificación de archivos, 1997.

Barroso Arahuetes, A., "Gestión Integral de Archivos en la diócesis de Bilbao”, en Lligall, núm. 19, 2002.

"El sistema archivístico para la diócesis de Bilbao", en I Congreso archivistico de las Américas. Archivos públicos y privados, Argentina, 2006.

"Carta circular de la Nunciatura Apostólica en España a los Reverendísimos Prelados sobre la reorganización de los archivos eclesiásticos (1929)", en Hispania Sacra, vol. VI, 1953, pp. 231-240.

Casares, M., Memoria de los Archivos diocesanos, Granada, 1964.

Catecismo de la Iglesia católica.

Código de Derecho Canónico de 1917, Madrid: BAC, 1999.

Código de Derecho Canónico de 1983, Madrid: Trivium, 1992.

Díaz García, A., "Archivo Diocesano Concentrado: la experiencia de Albacete", en Jornadas de Archivos e Investigación, Madrid: Ministerio de Cultura, 1996.

—_, Archivo Diocesano de Albacete. Inventario y Microfilm, Albacete: Obispado de Albacete, 1985.

Domato Búa, S., Archivo Histórico Diocesano de Santiago de Compostela. Inventario del Fondo General, Santiago de Compostela: Fundación Barrio de la Maza, 1988.

—_, Archivo Histórico Diocesano. Guía del Visitante, Santiago de Compostela: Archivo Histórico Diocesano, 1980.

Eliade, M., Historia de las Ideas y las Creencias Religiosas, Madrid: RBA, 2004.

Fernández Catón, J. M., Catálogo del Archivo Histórico Diocesano de León, León: Centro de Estudios San Isidoro, 1978-1986.

Fernández Fernández, J. M., "Los fondos del Archivo Diocesano de Mondoñedo”, en Estudios Mindonienses, 1985.

Floristan, A., "Fondos del Archivo Diocesano para el estudio de la Edad Media”, en Príncipe de Viana, vol. CCXXXI, 2004, pp. 29-52.

García Conde A., El Archivo Diocesano de Lugo, Sondeo Documental, Santiago de Compostela: Universidad, 1975.

Gil Domínguez, A., "Historia del Archivo Diocesano de Zaragoza", en Aragonia Sacra, vol. I, 1986.

González, M., Archivo Diocesano de Astorga. Memoria, Astorga, 1988.

Hernández Olivera, L., "Integración de los Archivos Eclesiásticos en el Sistema de Archivos de Castilla y León”, en Boletín ACAL, vol. 9, núm. 31, 1999, p. 39.

Hevia Ballina, A., Catálogo del Archivo Histórico Diocesano, Oviedo: Arciprestazgo de Aller, 1982.

—_, Guía del Archivo Histórico Diocesano, Oviedo: Comisión Diocesana del Patrimonio Artístico de la Iglesia, 1988.

Iguacen Borau, D., Diccionario del patrimonio cultural de la Iglesia, Madrid: Encuentro, 1999.

Jaramillo, M. A., "Documentación sobre órdenes religiosas en los Archivos Diocesanos”, en Memoria Ecclesiae, vol. VIII, 1995, pp. 393-399. 
Llanos, J., "Sistemas archivísticos y gestión de documentos", en XV Congreso Internacional de Archivos, Sevilla, 2000.

Marqués Planaguma, J. M., Arxiu Diocesà de Girona. Una etapa: llindar de Modest Prat, Gerona: Arxiu Diocesà de Girona, 1989.

—_, Arxiu Diocesà de Girona: guia-inventari, Gerona: Diputació, 1998.

Melgares, J., Archivo Histórico Diocesano de Jaén, Jaén, 1986.

Monachino, V. et al., Guida degli archivi diocesani d'Italia, Roma: Ministerio per I Beni Cultturali e Ambientali, 1990-1993.

Pérez Mier, L., "Diezmos y primicias en el Patrimonio Eclesiástico", en Fuentes de derecho público del patrimonio eclesiástico, Salamanca, 1950, pp. 45-64.

Pérez, D., Guía del Archivo Diocesano de Cuenca, Cuenca: Diputación, 1988.

Quintana, A., Memoria de actividades del Archivo Diocesano de Astorga, Astorga: Archivo Diocesano, 1983.

Roselló Lliteras, J., Tipología Documental del Archivo Diocesano de Mallorca, Palma de Mallorca: Dirección General de Cultura, 1986.

Rubio Merino, P., "Inventario del Archivo Diocesano de Coria-Cáceres”, en Inventario de Archivos Extremeños, Real Academia de Extremadura de las Letras y de las Artes, 1993.

__ , "La documentación Moderna en los Archivos Diocesanos", en Los Archivos de la Iglesia en España, León, 1978.

—_, Archivística Eclesiástica: Nociones básicas, Sevilla: Guadalquivir, 1999.

Sáez de Ocariz y Ruiz de Azúa, M., "El Archivo Diocesano de Logroño”, en Berceo, núm. 128, 1995, pp. 317-324.

Sales, J. e I. Ursúa, Catálogo del Archivo Diocesano de Pamplona, Pamplona: Gobierno de Navarra, 1995.

Salestirapu, J. L., El Archivo Diocesano de Pamplona, Vitoria: Facultad de Teología, 1981.

Vaquerizo, M., Inventario de libros del Archivo Diocesano de Santander, Madrid: Taurus, 1983. 